\title{
RET Proto-Oncogene and Thyroid Cancer
}

\section{Paul Komminoth, MD}

Address correspondence to

Dr. Paul Komminoth, Department of Pathology,

University of Zuirich,

Schmelzbergstrasse 12, $\mathrm{CH}-8091$

Zurich, Switzerland. E-mal:

paulkom@pathol.unizh.ch

This article was presented in part at the Endocrine Pathology

Society Companion Meeting of the USCAP in Orlando, FL,

March 1, 1997.

Endocrine Pathology, vol. 8, no. 3, 235-239, Fall 1997 (c) Copyright 1997 by Humana Press Inc. All rights of any nature whatsoever reserved. $1046-3976 / 97 / 8: 235-239 / \$ 9.25$

\begin{abstract}
The RET proto-oncogene has not only conclusively been identified as responsible for the three subtypes of the inherited cancer syndrome multiple endocrine neoplasia type 2 (MEN-2) but also shown to be involved in the molecular evolution of sporadic medullary and papillary thyroid carcinoma as well as Hirschsprung's disease. A variety of recent studies have elucidated the pathophysiological mechanisms leading to neoplastic disease and we now understand that dominant activating germline mutations lead to MEN-2A, MEN-2B, and familial MTC; somatic mutations to sporadic medullary thyroid carcinoma; RET rearrangements to papillary thyroid carcinoma; and inactivating alterations to Hirschsprung's disease. The clinical significance, however, of RET alterations especially in sporadic thyroid tumors is still controversial and therapeutic concepts in MEN-2 gene carriers only start to emerge. This article is a short summary of the recent findings on the structure and physiology of the RET proto-oncogene and its role in familial and sporadic thyroid cancer.
\end{abstract}

Key Words: RET Thyroid; medullary thyroid carcinoma; papillary thyroid carcinoma.

\section{Introduction}

There have been many recent advances in our understanding of thyroid disease, including the molecular biology of thyroid neoplasms. Recent reports have described the involvement of specific genetic alterations in different types of thyroid neoplasms: Ras point mutations are frequently observed in tumors with follicular histology and a high prevalence of $\mathrm{p} 53$ point mutations have been found in anaplastic carcinomas. More recent studies revealed that the $R E T$ proto-oncogene is involved in the tumorigenesis of medullary thyroid carcinoma (MTC) and papillary thyroid carcinoma by activation of its tyrosine kinase either by point mutation or rearrangement.

\section{The RET Proto-Oncogene}

The RET proto-oncogene (REarranged during Transfection) is located on chromosome $10 \mathrm{q} 11.2$, has 21 exons, and encodes a transmembrane receptor with cytoplasmic tyrosine kinase activity [1]. RET transcripts and protein are expressed in cells and neoplasms of neuroendocrine differentiation, including parafollicular $\mathrm{C}$ cells and MTCs, adrenal medulla and pheochromocytomas as well as neuroblastomas, parathyroid parenchymal cell precursors and peripheral nerves, neurofibromas, and schwannomas. The RET protein is a functional receptor for the glial-cell-line-derived neurotrophic factor (GDNF), a distant member of the transforming growth factor (TGF)- $\beta$ superfamily [2]. GDNF uses a multisubunit receptor system in which the GDNF receptor- $\alpha$ (GDNFR- $\alpha$ ) and $R E T$ function as the ligand-binding and signaling components, respectively [3].

\section{RET in Medullary Thyroid Carcinoma}

Several groups have demonstrated that distinct germline mutations in the RET 
proto-oncogene are associated with the dominantly inherited cancer syndromes multiple endocrine neoplasia type $2 \mathrm{~A}$ and 2B (MEN-2A and MEN-2B) and familial medullary thyroid carcinoma (FMTC) [4]. All three syndromes share heritable MTCs as part of the disease phenotype [5]. MEN-2A, which accounts for more than $90 \%$ of all cases of MEN-2, is characterized by the additional occurrence of pheochromocytoma and hyperparathyroidism resulting from parathyroid hyperplasia or adenoma. Activating mutations in the cysteine-rich extracellular region cause enhanced dimerization of the RET tyrosine kinase receptor and autophosphorylation, and are causative for MEN-2A and FMTC. Missense germline mutations in one of six codons for Cys in RET exons $10(609,611,618$, and 620) and 11 (630 and 634) have been identified in $97 \%$ of MEN-2A and $87 \%$ of FMTC families [4]. In FMTC families MTC is the only clinical feature and the course of the disease is more benign than that of MEN-2A or MEN-2B. In a few FMTC families, additional germline mutations have been identified at codons 768 and 804 in RET exons 13 and 14. The effects of these mutations are unclear. The former may alter kinase activity by changing the substrate specificity or the ATPbinding capacity of the receptor and the latter may activate the receptor by altering its interactions with normal cellular substrates or modifying the range of substrates the receptor can phosphorylate. In MEN-2B, which accounts for approx $5 \%$ of all patients with MEN-2, an activating mutation of the tyrosine kinase core domain has been identified in $94 \%$ of cases. This mutation at codon 918 in exon 16 replaces methionine with threonine and causes increased autophosphorylation and alteration of the substrate specificity of the tyrosine kinase. The MEN-2B syndrome is characterized by MTC and pheochro- mocytoma, rare involvement of parathyroids, myelinated corneal nerves, gastrointestinal ganglioneuromatosis, and a variety of skeletal abnormalities such as a marfanoid habitus, pes cavus, talipes equinovarus, slipped capital femoral epiphysis, kyphosis, scoliosis, and an increased joint laxity [5]. The thyroid tumors tend to occur at an earlier age and pursue a more aggressive course than in patients with MEN-2A and FMTC. The germline mutation in MEN-2B frequently represents new mutations (approx 50\%) and it appears that the mutant allele is paternally derived, even though the father does not carry a germ line mutant allele.

Somatic mutations in RET have also been found in a proportion of patients with sporadic MTCs. By far the most common mutation involves codon 918 (Met $\rightarrow$ Thr). This type of missense mutation in exon 16 has been described in $23-85 \%$ of sporadic MTCs; in our own series of 16 examined tumors we found $44 \%$ MTCs harboring this type of RET mutation [6]. Other groups found additional mutations at codon 768 of exon 13, at codon 883 of exon 15, at codon 634 of exon 11 , and in exon 10 in a small proportion of tumors [4]. Furthermore, microdeletions causing the loss of a Cys residue at codon 630 or 634 have been described in sporadic MTCs by several groups. The differences in mutational frequencies and codons involved that have been reported by various centers suggest that either regional and environmental or technical factors might be involved. Thus, in a recent study, Eng et al. [7] examined microdissected subpopulations from sporadic MTCs and multiple metastases from these tumors and found that approx $80 \%$ of sporadic MTCs had at least one subpopulation with the RET codon 918 mutation. The distribution of this mutation was nonhomogeneous, occurring only in subpopulations in most 
tumors and among subsets of multiple metastases. These findings suggest either that the codon 918 mutation can arise as an event in progression within a metastatic clone, or that MTC can be of polyclonal origin. In the same study the authors also reported that one of two MTCs from MEN-2A patients carried a somatic mutation at codon 918 in addition to the RET mutation present in the germline.

Recently, two groups have reported that somatic mutations of the RET protooncogene in sporadic MTCs were significantly correlated with a poor outcome, whereas others have demonstrated that the presence or absence of the somatic mutation at the RET codon 918 was not correlated with clinical data, including most recent follow-up $[8,9]$. Thus, the clinical significance of RET mutations in sporadic MTCs remains to be elucidated on larger series of patients with long-time followup data.

We and others have demonstrated that the analysis of germline DNA for RET mutations may be helpful to determine the hereditary or sporadic nature of MTCs [10] and that DNA analysis can also be performed on DNA extracted from paraffinembedded tissues [11]. The absence of a germline RET exon $10,11,13,14$, or 16 mutation appears to rule out MEN-2A, MEN-2B, or FMTC to a high probability, although a familial form of MTC other than classical MEN-2 cannot be excluded conclusively. Furthermore, the presence of a few MEN-2 families without detectable RET mutations indicate that this disease might also be caused by germline mutations in the gene encoding the GDNFR- $\alpha$ or other genes.

\section{RET in Papillary Thyroid Carcinoma}

The RET proto-oncogene has also been implicated in the causation of papillary thyroid carcinoma (PTC). It has been shown that RET is activated through somatic rearrangements in a subset of PTCs. The RET/PTC oncogenes, rearranged forms of the $R E T$ proto-oncogene, encode fusion proteins in which proto-RET tyrosine kinase and $C$-terminal domains are fused to different donor genes. The respective RET/PTC oncoproteins display constitutive tyrosine kinase activity and tyrosine phosphorylation. Three major forms of the RET/PTC oncogene have been identified: the RET/PTC-1 oncogene (where c-RET rearranges with the $\mathrm{H} 4$ gene D10S170 on chromosome 10q21), the $R E T / \mathrm{PTC}-2$ oncogene (where $\mathrm{c}-R E T$ rearranges with the regulatory subunit $\mathrm{R} 1$ alpha of the protein kinase $A$ on $17 q 23$ ), and the RET/PTC-3 oncogene (where $c-R E T$ rearranges with the RFG2/Ele1 gene on 10q11.2). Thus, the two most common forms, RET/PTC-1 and RET/PTC-3, both result from a paracentric inversion of the long arm of chromosome 10 [12]. More recently, a novel type of Ele1/RET rearrangement designated RET/PTC-4 has been described in which the exon 5 of Ele1 is joined to exon 11 instead of exon 12 of $R E T$ and the cDNA sequence is 93 nucleotides larger than the regular one [13]. The RET/ PTC-4 oncogene has been found in a post-Chernobyl PTC, indicating that targeted radiation effects could be responsible for the atypical $R E T$ rearrangement.

Wide differences $(2.5-60 \%)$ in frequency of $R E T$ activation by RET/PTC in PTCs of different populations have been reported, and it is not clear whether these are owing to environmental factors, racial differences, or technical reasons. However, several studies have shown an association between ionizing radiation and development of PTC. In addition, in vitro irradiation of tumor cell lines induced rearrangements of $R E T$ similar to those observed in human PTCs. These two observations could be 
related to the reported increased incidence of PTCs in children living in contaminated areas around Chernobyl. However, it has recently been demonstrated that age, per se, also plays a role in the development of RET positive PTCs [14]. Furthermore, it has been shown that $R E T / \mathrm{PTC}$ activation is present in 11 of $26(42 \%)$ occult PTCs and therefore concluded that RETI PTC rearrangement represents an early event in the process of thyroid cell transformation [15].

The clinical relevance of $R E T /$ PTC rearrangements in PTCs is controversial. Some have suggested that RET/PTC expression could serve as an indicator of aggressive behavior in PTCs, specifically for distant metastatic disease. In a recent study, Sugg et al. [16] analyzed 60 thyroid carcinomas by RT-PCR for RET/P'TC expression to determine a possible correlation with clinical data or tumor morphology. They found RET/PTC oncogene rearrangements in 3 of $60(5 \%)$ PTCs of young patients ( $<45 \mathrm{yr}$ of age) with small thyroid carcinomas showing a predisposition for lymphatic involvement, suggesting a possible role in the development of this subgroup of tumors. Thus, more data are necessary to determine whether molecular analysis of $R E T / \mathrm{PTC}$ rearrangements are required in patients with PTCs.

In addition to the tumor types mentioned, $R E T$ appears also to be causative for $10-40 \%$ of cases with Hirschsprung's disease [17] with or without MEN-2 [18], but seems not to be generally important in the formation of sporadic neuroendocrine tumors other than MTC and pheochromocytoma [6].

\section{Summary and Conclusion}

A variety of recent studies on the $R E T$ proto-oncogene have elucidated the patho- physiological mechanisms leading to neoplastic disease; we now understand that dominant activating germline mutations lead to MEN-2A, MEN-2B, and FMTC; somatic mutations to sporadic MTCs; RET rearrangements to PTCs; and inactivating alterations to Hirschsprung's disease. The clinical significance of $R E T$ alterations, especially in sporadic thyroid tumors, however, is still controversial and therapeutic concepts in MEN-2 gene carriers only start to emerge. Furthermore, a substantial proportion of sporadic MTCs and especially PTCs do not show RET mutations or activation and are likely caused by other genetic alterations. Several candidate genes, such as the GDNF and GDNFR- $\alpha$ [19], are currently under investigation and it is anticipated that the near future will bring new insights into the tumorigenesis of sporadic as well as hereditary thyroid carcinoma.

\section{Acknowledgments}

I am grateful to $S$. Muletta-Feurer and P. Saremaslani for their excellent technical assistance.

\section{References}

1. Lloyd RV. RET proto-oncogene mutations and rearrangements in endocrine diseases [comment]. Am J Pathol 147:1539-1544, 1995.

2. Durbec P, Marcos GC, Kilkenny C, Grigoriou M, Wartiowaara K, Suvanto P, Smith D, Ponder B, Costantini F, Saarma M, Sariola H, Pachnis V. GDNF signalling through the Ret receptor tyrosine kinase. Nature 381:789793, 1996.

3. Treanor JJ, Goodman L, de Sauvage F, Stone DM, Poulsen KT, Beck CD, Gray C, Armanini MP, Pollock RA, Hefti F, Phillips HS, Goddard A, Moore MW, Buj BA, Davies AM, Asai N, Takahashi M, Vandlen R, Henderson $\mathrm{CE}$, Rosenthal A. Characterization of a multicomponent receptor for GDNF [see comments]. Nature 382:80-83, 1996. 
4. Eng C. The RET proto-oncogene in multiple endocrine neoplasia type 2 and Hirschsprung's disease. N Engl J Med 335:943-951, 1996.

5. De Lellis RA. Multiple endocrine neoplasia syndromes revisited. Clinical, morphologic and molecular features. Lab Invest 72:494$505,1995$.

6. Komminoth P, Roth J, Muletta-Feurer S, Saremaslani P, Seelentag WKF, Matias-Guiu X, Heitz PU. RET proto-oncogene point mutations in sporadic neuroendocrine tumors. J Clin Endocrinol Metab 81:2041-2046, 1996.

7. Eng C, Mulligan LM, Healey CS, Houghton C, Frilling A, Raue F, Thomas GA, Ponder BA. Heterogeneous mutation of the RET proto-oncogene in subpopulations of medullary thyroid carcinoma. Cancer Res 56:2167-2170, 1996.

8. Zedenius J, Larsson C, Bergholm U, Bovee J, Svensson A, Hallengren B, Grimelius L, Backdahl M, Weber G, Wallin G. Mutations of codon 918 in the RET proto-oncogene correlate to poor prognosis in sporadic medullary thyroid carcinomas. J Clin Endocrinol Metab 80: 3088-3090, 1995.

9. Marsh DJ, Learoyd DL, Andrew SD, Krishnan L, Pojer R, Richardson AL, Delbridge L, Eng $\mathrm{C}$, Robinson BG. Somatic mutations in the RET proto-oncogene in sporadic medullary thyroid carcinoma. Clin Endocrinol Oxf 44:249-257, 1996.

10. Komminoth P, Kunz EK, Hiort O, MatiasGuiu X, Christiansen G, Roth J, Heitz PU. Analysis of RET proto-oncogene point mutations distinguishes heritable from nonheritable medullary thyroid carcinomas. Cancer 76: 479-489, 1995.

11. Komminoth P, Muletta-Feurer $S$, Saremaslani P, Kunz EK, Matias-Guiu X, Hiort O, Schroder S, Seelentag WKF, Roth J, Heitz PU. Molecular diagnosis of multiple endocrine neoplasia (MEN) in paraffin-embedded specimens. Endocr Pathol 6:267-278, 1995.

12. Jhiang SM, Mazzaferri EL. The ret/PTC oncogene in papillary thyroid carcinoma. J Lab Clin Med 123:331-337, 1994.
13. Fugazzola L, Pierotti MA, Vigano E, Pacini F, Vorontsova TV, Bongarzone I. Molecular and biochemical analysis of RET/PTC4 a novel oncogenic rearrangement between RET and ELE1 genes, in a post-Chernobyl papillary thyroid cancer. Oncogene 13:10931097, 1996.

14. Bongarzone I, Fugazzola L, Vigneri P, Mariani L, Mondellini P, Pacini F, Basolo F, Pinchera A, Pilotti S, Pierotti MA. Age-related activation of the tyrosine kinase receptor protooncogenes RET and NTRK1 in papillary thyroid carcinoma. J Clin Endocrinol Metab 81: 2006-2009, 1996.

15. Viglietto G, Chiappetta G, Martinez Tello F, Fukunaga FH, Tallini G, Rigopoulou D, Visconti R, Mastro A, Santoro M, Fusco A. RET/PTC oncogene activation is an early event in thyroid carcinogenesis. Oncogene 11:1207-1210, 1995.

16. Sugg SL, Zheng L, Rosen IB, Freeman JL, Ezzat S, Asa SL. ret/PTC-1, -2 , and -3 oncogene rearrangements in human thyroid carcinomas: implications for metastatic potential? J Clin Endocrinol Metab 81: 3360-3365, 1996.

17. Carlomagno F, De VG, Berlingieri MT, de Franciscis V, Melillo RM, Colantuoni V, Kraus MH, Di Fiore P, Fusco A, Santoro M. Molecular heterogeneity of RET loss of funcrion in Hirschsprung's disease. Embo J 15:27172725, 1996.

18. Mulligan LM, Eng C, Attié T, Lyonnet $S$, Marsh DJ, Hyland VJ, Robinson BG, Frilling A, Verellen-Dumoulin C, Safar A, Venter DJ, Munnich A, Ponder BAJ. Diverse phenotypes associated with exon 10 mutations of the RET proto-oncogene. Human Molecular Genetics 3: 2163-2167, 1994.

19. Dahia PLM, Toledo SPA, Mulligan LM, Maher ER, Grossman AB, Eng C. Mutation analysis of glial cell line-derived neurotrophic factor (GDNF), a ligand for the RET/GDNF receptor $\alpha$ complex, in sporadic phaeochromocytomas. Cancer Res 57:310-313, 1997. 